\section{JURNAL EKONOMI EFEKTIF}

ISSN : $2622-8882$, E-ISSN : 2622-9935

Jurnal Ekonomi Efektif, Vol. 4, No. 1, Oktober 2021 @Prodi Manajemen Fakultas Ekonomi Universitas

Pamulang

\title{
PENGARUH BUDAYA ORGANISASI TERHADAP PRODUKTIVITAS KARYAWAN PADA PT BERDIKARI PONDASI UTAMA DI JAKARTA BARAT
}

\author{
Sri Mulyani ${ }^{1 *}$, Aidil Amin Effendy ${ }^{2}$, Mahnun Mas'adi', \\ Guruh Dwi Pratama ${ }^{4}$, Arga Teriyan ${ }^{5}$ \\ Universitas Pamulang, Tangerang Selatan, Banten, Indonesia \\ dosen02246@unpam.ac.id*
}

Manuskrip: Agustus -2021; Ditinjau: September: -2021; Diterima: September-2021; Online: Oktober-2021; Diterbitkan: Oktober-2021

\begin{abstract}
ABSTRAK
Penelitian ini bertujuan untuk mengetahui pengaruh budaya organisasi terhadap produktivitas karyawan pada PT. Berdikari Pondasi Utama di Jakarta Barat.Metode yang digunakan adalah explanatory research dengan sampel sebanyak 68 responden. Teknik analisis menggunakan analisis statistik dengan pengujian regresi, korelasi, determinasi dan uji hipotesis.Hasil penelitian ini variabel budaya organisasi diperoleh nilai rata-rata skor sebesar 3,794 dengan kriteria baik. Variabel produktivitas karyawan diperoleh nilai rata-rata skor sebesar 3,876 dengan kriteria baik. Budaya organisasi berpengaruh positif dan signifikan terhadap produktivitas karyawan dengan nilai persamaan regresi $\mathrm{Y}=12,965+0,680 \mathrm{X}$, dan nilai koefisien korelasi 0,794 atau memiliki tingkat hubungan yang kuat dengan nilai determinasi 63,0\%. Uji hipotesis diperoleh signifikansi $0,000<0,05$.
\end{abstract}

\section{Kata Kunci: Motivasi Kerja, Lingkungan Kerja, Kinerja Karyawan}

\begin{abstract}
This study aims to determine the influence of organizational culture on employee productivity at PT. Berdikari Foundation Main in West Jakarta. The method used is explanatory research with a sample of 68 respondents. The analysis technique uses statistical analysis with regression testing, correlation, determination and hypothesis testing. The results of this study of organizational culture variables obtained an average score of 3.794 with good criteria. Employee productivity variable obtained an average score of 3.876 with good criteria. Organizational culture has a positive and significant effect on employee productivity with the value of the regression equation $Y=12,965+0.680 X$, and the correlation coefficient value of 0.794 or has a strong relationship level with a determination value of 63.0\%. Hypothesis testing obtained a significance of $0.000<0.05$.
\end{abstract}

Keywords: Work Motivation, Work Environment, Employee Performance 


\section{PENDAHULUAN}

\section{A. Latar Belakang Masalah}

Dalam suatu organisasi peran sumber daya manusia menjadi faktor yang menentukan tingkat keberhasilan yang ingin dicapai perusahaan, mengingat peran dan fungsi sumber daya manusia yang dimiliki manajemen dapat menentukan faktor keberhasilan produksi, membangun, serta mengembangkan perusahaan capaiannya. Selain itu, keberadaaan dari SDM ini juga merupakan faktor kunci dalam menentukan keberhasilan dan kesuksesan pada sebuah perusahaan atau organisasi.

merupakan komponen utama suatu organisasi yang menjadi perencanaan dan pelaku aktif dalam setiap aktifitas organisasi. Masalah sumber daya manusia merupakan aspek yang paling penting bagi kelangsungan hidup suatu perusahaan. Bila aspek ini melemah tentunya tujuan dari perusahaan tidak akan tercapai secara efektif dan efisien.

Kecenderungan global yang semakin kompetitif tersebut berpengaruh kuat pada budaya organisasi. Budaya dalam suatu organisasi, baik organisasi pemerintahan maupun swasta mencerminkan penampilan organisasi, bagaimana organisasi dilihat oleh orang yang berada di luarnya. Organisasi yang mempunyai budaya positif akan menunjukkan citra positif pula, demikian pula sebaliknya, apabila budaya organisasi tidak berjalan baik akan memberikan citra negatif bagi organisasi.

Budaya organisasi merupakan sebuah persepsi umum yang dipegang oleh anggota organisasi, suatu sistem tentang keberartian bersama. (Robbins dalam Wibowo (2016). Konflik tersebut ditunjukkan dengan pekerjaan yang terlihat kurang efisien. Banyak karyawan yang tidak dapat memanfaatkan waktu kerja di siang hari dengan baik, akibatnya mereka terlalu sering lembur hingga malam dikarenakan mengejar deadline yang telah ditetapkan setiap bulannya. Karena mereka yang bekerja di bagian redaksi beralasan bahwa terkadang inspirasi baru didapatkan pada malam hari. Padahal hal itu mengakibatkan membengkaknya biaya operasional perusahaan tiap bulannya.

Kenyataan menunjukkan banyak organisasi yang mengalami kemunduran karena ketidakmampuannya menyesuaikan diri dengan perubahan lingkungan. Perubahan budaya diperlukan paling tidak untuk dapat bertahan terhadap goncangan yang timbul sebagai akibat dari perubahan lingkungan.

Untuk bertahan terhadap lingkungan yang menantang di masa depan, Gogirl! Magazine perlu membicarakan masalah budaya organisasi. Organisasi tidak lagi dapat mengusahakan solusi dalam jangka pendek atau secara cepat. Mengembangkan budaya organisasi yang benar akan memerlukan waktu lebih lama untuk brainstorming. Diperlukan komitmen jangka panjang untuk menanamkan perlunya core values dan mendapatkan orang mempraktikan secara spesifik perilaku untuk mendapatkan budaya dan hasil yang diinginkan, tetapi usaha yang dilakukan akan berharga. Penelusuran akan perlunya perubahan budaya organisasi harus dilakukan sejak dini, karena proses perubahan budaya akan memerlukan waktu lama untuk memberikan hasil. Semakin lama organisasi menunggu untuk menjalankan proses, maka semakin sulit tugas.

Suatu organisasi dibentuk untuk mencapai suatu tujuan tertentu. Tujuan adalah sesuatu yang diharapkan organisasi untuk dicapai. Tujuan organisasi dapat berupa perbaikan pelayanan pelanggan, pemenuhan permintaan pasar, peningkatan kualitas produk atau jasa, meningkatnya daya saing, dan meningkatnya produktivitas karyawan.

Keberhasilan suatu organisasi sangat erat kaitannya dengan kualitas kerja para anggotanya, sehingga organisasi dituntut untuk selalu mengembangkan dan meningkatkan produktivitas dari para karyawan. Produktivitas karyawan berarti hasil kerja yang dapat ditampilkan atau penampilan kerja seseorang karyawan. Dengan 
demikian produktivitas seorang karyawan dapat diukur dari hasil kerja, hasil tugas, atau hasil kegiatan dalam kurun waktu tertentu. (Notoatmodjo, 2015:124)

Produktivitas yang dimiliki oleh karyawan PT. Berdikari Pondasi Utama masih belum optimal. Karyawan kurang semangat bekerja karena merasa kebutuhan baik fisik dan non fisik belum terpenuhi. Padahal produktivitas perusahaan sangat ditentukan oleh produktivitas karyawan yang menjadi ujung tombak kantor itu. Seorang karyawan memiliki andil atas setiap pekerjaan yang diberikan oleh perusahaan. Namun masih banyak karyawan yang belum mampu untuk menyelesaikan pekerjaan dengan baik. Terkadang masalah itu terjadi karena kurangnya loyalitas dan rasa memiliki atas perusahaan.

Tujuan mendasar dari pengukuran produktivitas adalah untuk mengidentifikasi kelemahan. Pengukuran produktivitas membantu menemukan kelemahan perusahaan, dimana kelemahan ini akan dimanfaatkan sebagai landasan perancangan strategi memperbaiki atau meminimalisir kelemahan tersebut.

Selain hal tersebut di atas, produktivitas karyawan juga dapat dilihat dari hasil kerja yang dihasilkan dalam satu waktu periode tertentu. Perusahaan telah menetapkan target yang telah disepakati pada saat Rapat Kerja Tahunan. Namun beberapa divisi belum dapat mencapai target tersebut dikarenakan hal-hal dari luar maupun dalam perusahaan.

Berdasarkan latar belakang yang sudah diuraikan di atas, maka Penulis mengambil judul "Pengaruh Budaya Organisasi Terhadap Produktivitas Karyawan Pada PT. Berdikari Pondasi Utama di Jakarta Barat".

\section{B. Rumusan Masalah}

1. Bagaimana budaya organisasi pada PT. Berdikari Pondasi Utama di Jakarta Barat?.

2. Bagaimana produktivitas karyawan pada PT. Berdikari Pondasi Utama di Jakarta Barat?

3. Adakah pengaruh antara budaya organisasi terhadap produktivitas karyawan pada PT. Berdikari Pondasi Utama di Jakarta Barat?.

\section{Tujuan Penelitian}

1. Untuk mengetahui kondisi budaya organisasi pada PT. Berdikari Pondasi Utama di Jakarta Barat.

2. Untuk mengetahui kondisi produktivitas karyawan pada PT. Berdikari Pondasi Utama di Jakarta Barat.

3. Untuk mengetahui pengaruh budaya organisasi terhadap produktivitas karyawan pada PT. Berdikari Pondasi Utama di Jakarta Barat.

\section{TINJAUAN PUSTAKA}

\section{Budaya organisasi}

Menurut Rivai dan Mulyadi (2012:) menyatakan bahwa budaya organisasi adalah suatu kerangka kerja yang menjadi pedoman tingkah laku sehari-hari dan membuat keputusan untuk karyawan dan mengarahkan tindakan mereka untuk mencapai tujuan organisasi.

\section{Produktivitas Karyawan}

Menurut Sinungan dalam Busro (2018), produktivitas kerja merupakan kemampuan seseorang atau sekelompok orang untuk menghasilkan barang dan jasa dalam waktu tertentu yang telah ditentukan atau sesuai dengan rencana 


\section{METODE PENELITIAN}

\section{Populasi}

Yang dijadikan sebagai populasi dalam penelitian ini adalah responden yang berjumlah 68 responden PT. Berdikari Pondasi Utama di Jakarta Barat

\section{Sampel}

Teknik pengambilan sampling dalam penelitian ini adalah sampel jenuh, dimana semua anggota populasi dijadikan sebagai sampel. Dengan demikian sampel dalam penelitian ini sampel yang digunakan berjumlah 68 responden.

\section{Jenis Penelitian}

Jenis penelitian yang dipakai adalah asosiatif, dimana tujuannya adalah untuk mengetahui atau mencari keterhubungan antara variabel independen terhadap variabel dependennya

\section{Metode Analisis Data}

Dalam menganalisis data digunakan uji validitas, uji reliabilitas, analisis regresi linier sederhana, analisis koefisien korelasi, analisis koefisien determinasi dan pengujian hipotesis.

\section{HASIL PENELITIAN}

\section{Analisis Deskriptif}

Pada pengujian ini digunakan untuk mengetahui skor minimum dan maksimum skor tertinggi, ratting score dan standar deviasi dari masing-masing variabel. Adapun hasilnya sebagai berikut:

Tabel 1. Hasil Analisis Descriptive Statistics

Descriptive Statistics

\begin{tabular}{cc|c|c|c|c} 
& N & Minimum & Maximum & Mean & Std. Deviation \\
\hline Budaya organisasi (X) & 68 & 27 & 49 & 37.94 & 4.600 \\
\hline Produktivitas Karyawan (Y) & 68 & 30 & 50 & 38.76 & 3.940 \\
\hline Valid N (listwise) & 68 & & & & \\
\hline
\end{tabular}

Budaya organisasi diperoleh varians minimum sebesar 27 dan varians maximum 49 dengan ratting score sebesar 3,794 dengan standar deviasi 4,600. Skor ini termasuk pada rentang sakala 3,40 - 4,19 dengan kriteria baik atau setuju. Produktivitas karyawan diperoleh varians minimum sebesar 30 dan varians maximum 50 dengan ratting score sebesar 3,876 dengan standar deviasi 3,940. Skor ini termasuk pada rentang sakala 3,40 - 4,19 dengan kriteria baik atau setuju.

\section{Analisis Kuantitatif}

Pada analisis ini dimaksudkan untuk mengetahui pengaruh variabel independen terhadap variabel dependen. Adapun hasil pengujian sebagai berikut:

\section{a. Analisis Regresi Linier Sederhana}

Uji regresi ini dimaksudkan untuk mengetahui perubahan variabel dependen jika variabel independen mengalami perubahan. Adapun hasil pengujiannya sebagai berikut:

Tabel 2. Hasil Pengujian Regresi Linier Sederhana

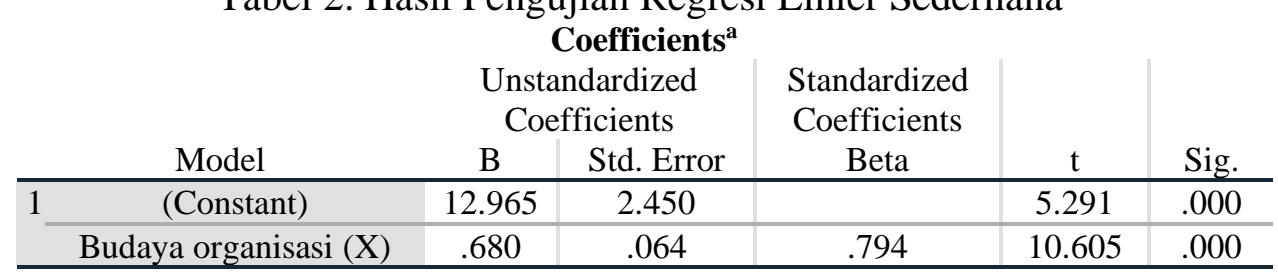


Berdasarkan hasil pengujian pada tabel di atas, diperoleh persamaan regresi $\mathrm{Y}$ $=12,965+0,680 \mathrm{X}$. Dari persamaan tersebut dijelaskan sebagai berikut:

1) Konstanta sebesar 12,965 diartikan jika budaya organisasi tidak ada, maka telah terdapat nilai produktivitas karyawan sebesar 12,965 point.

2) Koefisien regresi budaya organisasi sebesar 0,680, angka ini positif artinya setiap ada peningkatan budaya organisasi sebesar 0,680 point maka produktivitas karyawan juga akan mengalami peningkatan sebesar 0,680 point.

\section{b. Analisis Koefisien Korelasi}

Analisis koefisien korelasi dimaksudkan untuk mengetahui tingkt kekuatan hubungan dari variabel independen terhadap variabel dependen baik secara parsial maupun simultan. Adapun hasil pengujian sebagai berikut:

Tabel 3. Hasil Pengujian Koefisien Korelasi Budaya organisasi Terhadap

\section{Produktivitas Karyawan. Correlations $^{\mathrm{b}}$}

\begin{tabular}{ccc|c} 
& & $\begin{array}{c}\text { Budaya } \\
\text { organisasi (X1) }\end{array}$ & $\begin{array}{c}\text { Produktivitas } \\
\text { Karyawan (Y) }\end{array}$ \\
\hline Budaya organisasi (X) & Pearson Correlation & 1 & $.794^{* *}$ \\
\cline { 2 - 4 } & Sig. (2-tailed) & & .000 \\
\hline \multirow{2}{*}{$\begin{array}{c}\text { Produktivitas Karyawan } \\
\text { (Y) }\end{array}$} & Pearson Correlation & $.794^{* *}$ & 1 \\
\cline { 2 - 4 } & Sig. (2-tailed) & .000 & \\
\hline
\end{tabular}

Berdasarkan hasil pengujian diperoleh nilai korelasi sebesar 0,794 artinya budaya organisasi memiliki hubungan yang kuat terhadap produktivitas karyawan.

\section{c. Analisis Koefisien Determinasi}

Analisis koefisien determinasi dimaksudkan untuk mengetahui besarnya persentase pengaruh dari variabel independen terhadap variabel dependen baik secara parsial maupun simultan. Adapun hasil pengujian sebagai berikut:

Tabel 4. Hasil Pengujian Koefisien Determinasi Budaya organisasi Terhadap Produktivitas Karyawan.

Model Summary

\begin{tabular}{|c|c|c|c|c|}
\hline \multicolumn{5}{|c|}{ 1780 } \\
\hline Model & $\mathrm{R}$ & R Square & $\begin{array}{c}\text { Adjusted R } \\
\text { Square }\end{array}$ & $\begin{array}{l}\text { Std. Error of the } \\
\text { Estimate }\end{array}$ \\
\hline 1 & $.794^{\mathrm{a}}$ & .630 & .625 & 2.414 \\
\hline
\end{tabular}

Berdasarkan hasil pengujian diperoleh nilai determinasi sebesar 0,630 artinya budaya organisasi memiliki kontribusi pengaruh sebesar $63,0 \%$ terhadap produktivitas karyawan, sedangkan sisanya sebesar $37,0 \%$ dipengaruhi oleh faktor lain yang tidak dilakukan penelitian.

\section{d. Uji Hipotesis}

\section{Uji hipotesis Parsial (Uji t)}

Pengujian hipotesis dengan uji t digunakan untuk mengetahui hipotesis parsial mana yang diterima.

Hipotesis pertama: Terdapat pengaruh yang signifikan budaya organisasi terhadap produktivitas karyawan.

Tabel 5. Hasil Uji Hipotesis Budaya organisasi Terhadap Produktivitas Karyawan.

\section{Coefficients ${ }^{\mathrm{a}}$}

Unstandardized

Coefficients

\begin{tabular}{|c|c|c|c|c|c|c|}
\hline \multirow{2}{*}{\multicolumn{2}{|c|}{ Model }} & \multicolumn{2}{|c|}{ Coefficients } & \multirow{2}{*}{$\begin{array}{c}\text { Coefficients } \\
\text { Beta }\end{array}$} & & \multirow[b]{2}{*}{ Sig. } \\
\hline & & $\mathrm{B}$ & Std. Error & & & \\
\hline & (Constant) & 12.965 & 2.450 & & 5.291 & .000 \\
\hline & Budaya organisasi $(\mathrm{X})$ & 680 & .064 & .794 & 10.605 & .000 \\
\hline
\end{tabular}


Berdasarkan hasil pengujian pada tabel di atas, diperoleh nilai t hitung $>\mathrm{t}$ tabel atau $(10,605>2,000)$, dengan demikian hipotesis yang diajukan bahwa terdapat pengaruh yang signifikan atara budaya organisasi terhadap produktivitas karyawan diterima.

\section{Pembahasan Hasil Penelitian}

\section{Jawaban Responden Budaya Organisasi}

Berdasarkan jawaban responden, variabel budaya organisasi diperoleh ratting score sebesar 3,794 berada di rentang skala 3,40 - 4,19 dengan kriteria baik atau setuju.

\section{Jawaban Responden Variabel Produktivitas Karyawan}

Berdasarkan jawaban responden, variabel produktivitas karyawan diperoleh ratting score sebesar 3,876 berada di rentang skala 3,40-4,19 dengan kriteria baik atau setuju.

\section{Pengaruh Budaya organisasi Terhadap Produktivitas Karyawan}

Budaya organisasi berpengaruh signifikan terhadap produktivitas karyawan dengan persamaan regresi $\mathrm{Y}=12,965+0,680 \mathrm{X}$, nilai korelasi sebesar 0,794 atau memiliki hubungan yang kuat dengan kontribusi pengaruh sebesar $63,0 \%$. Pengujian hipotesis diperoleh nilai t hitung $>\mathrm{t}$ tabel atau $(10,605>2,000)$. Dengan demikian hipotesis yang diajukan bahwa terdapat berpengaruh signifikan antara budaya organisasi terhadap produktivitas karyawan diterima.

\section{KESIMPULAN DAN SARAN}

\section{Kesimpulan}

a. Variabel budaya organisasi diperoleh ratting score sebesar 3,794 berada di rentang skala 3,40-4,19 dengan kriteria baik atau setuju.

b. Variabel produktivitas karyawan diperoleh ratting score sebesar 3,876 berada di rentang skala 3,40-4,19 dengan kriteria baik atau setuju.

c. Budaya organisasi berpengaruh signifikan terhadap produktivitas karyawan dengan persamaan regresi $\mathrm{Y}=12,965+0,680 \mathrm{X}$, nilai korelasi sebesar 0,794 atau kuat dan kontribusi pengaruh sebesar $63,0 \%$ sedangkan sisanya sebesar $37,0 \%$ dipengaruhi faktor lain. Uji hipotesis diperoleh nilai $t$ hitung $>t$ tabel atau $(10,605>2,000)$.

\section{Saran}

a. Manajemen harus selalu menjelaskan Visi organisasi/Perusahaan. Untuk membangun budaya kerja positif pertama-tama perusahaan harus mampu memberikan visi yang jelas kepada para karyawannya

b. Perusahaan harus melakukan perencanaan kerja secara baik karena dengan perencanaan yang baik akan memudahkan manajemen untuk menentukan langkahlangkah yang strategis untuk mencapai suatu tujuan.

\section{DAFTAR PUSTAKA}

Abdullah, M (2014) Manajemen dan Evaluasi Produktivitas Karyawan, Yogyakarta: Penerbit Aswaja Pressindo.

Algifari. (2015). “Analisis Regresi untuk Bisnis dan Ekonomi”. Yogyakarta: BPFE.

AM, E. N., et al. (2020). Pengaruh Pendidikan Dan Pelatihan Terhadap Kinerja Pegawai Direktorat Standarisasi Dan Pengendalian Mutu Kementerian Perdagangan. Diklat Review: Jurnal manajemen pendidikan dan pelatihan, 4(3), 220-226. 
Arikunto, Suharsimi (2014). "Prosedur Penelitian Suatu Pendekatan Praktek". Jakarta Barat: Rineka Cipta.

Bangun, Wilson. 2012. "Manajemen Sumber Daya Manusia". Jakarta Barat: Erlangga

Bejo Siswanto (2013) Manajemen Tenaga Kerja Rancangan dalam Pendayagunaan dan Pengembangan Unsur Tenaga Kerja”, Bandung: Sinar Baru.

Dessler, G. (2006.) Manajemen Sumber Daya Manusia (Jilid II). Jakarta Barat: Indeks.

Edi Sutrisno (2016). Manajemen Sumber Daya Manusia. Jakarta Barat: Prenadamedia Group.

George Terry R \& Rue, Leslie W. Rue (2016) Dasar-Dasar Manajemen, Jakarta Barat Bumi Aksara.

Gerry Dessler (2016) Human Resources Management, Prenticehall, London: International Inc.

Handoko (2016) Manajemen Personalia dan Sumberdaya Manusia. Yogyakarta: BPFE.

Hasibuan, Malayu S.P. (2016). Manajemen Sumber Daya Manusia. Edisi Revisi. Jakarta Barat: PT Bumi Aksara.

Imam Ghozali (2017). “Aplikasi Analisis Multivariate Dengan Program SPSS”. Edisi Kelima. Semarang: Badan Penerbit Undip.

Istijanto (2014) "Riset Sumber Daya Manusia”. Jakarta Barat: PT. Gramedia Pustaka

Kustini, E., et al. (2021). Pengaruh Keterampilan Kerja Dan Lingkungan Kerja Terhadap Kinerja Karyawan Pada PT. Garuda Daya Pratama Sejahtera (Garuda Indonesia Group). Jurnal Ilmiah PERKUSI, 1(3), 305-314.

Luthans Fred (2014) Organizational Behavior, Ney York: McGraw-Hill, New York.

Mangkunegara, Prabu Anwar. (2016). Evaluasi Produktivitas SDM. Cetakan ke tujuh, PT Refika Aditama: Bandung.

Marimin, M., \& Sunarsi, D. (2021). Pengaruh Komunikasi Organisasi terhadap Kepuasan Kerja pada PT. Finance Multi Abadi di Jakarta. Jurnal Tadbir Peradaban, 1(1), 1521.

Nurjaya, N., et al. (2021). Pengaruh Kompetensi Sumber Daya Manusia Dan Kemampuan Pemanfaatan Teknologi Terhadap Kinerja Aparatur Desa Pada Kantor Kepala Desa Di Kabupaten Gunungkidul, Yogyakarta. JENIUS (Jurnal Ilmiah Manajemen Sumber Daya Manusia), 4(3), 332-346.

Robbins, P.S, \& Judge, A.T. (2003). Organizational Behavior. Jakarta Barat: Salemba Empat.

Santoso, Singgih (2015). “Menguasai Statistik Multivariat”. Jakarta Barat: PT Elex Media Komputindo.

Sedarmayanti (2016) Manajemen Sumber Daya Manusia, Reformasi Birokrasi dan Manajemen Karyawan Negeri Sipil, Cetakan Kelima, Bandung: PT Refika Aditama. Sudjana (2014) “Metode Statistika”, Bandung: Tarsido.

Sugiyono (2017), "Metode Penelitian Administrasi : dilengkapi dengan Metode $R \&$ D”. Bandung: Alfabeta.

Veithzal Rivai (2015) Manajemen Sumber Daya Manusia Untuk Perusahaan, Jakarta Barat: Raja Grafindo Persada.

Wibowo (2015) Manajemen Produktivitas, Jakarta Barat: PT. Raja Grafindo Persada. 